\title{
Metastatic Renal Cell Carcinoma to Submandibular Gland: A Rare Occurrence
}

Carlo Melloni ${ }^{1 *}$, Nino Dispensa ${ }^{2}$, Adriana Tuttolomondo $^{1}$, Guglielmo Melloni $^{3}$ and Adriana Cordova $^{1}$

${ }^{1}$ Department of Surgical, Oncological and Oral Sciences, Plastic and Reconstructive Surgery Unit, University of Palermo, Italy

${ }^{2}$ Department of Medicine, Cardiovascular and Nephrourological Disease - Urology, University of Palermo Italy

${ }^{3}$ Division of Urology, Department of Surgical Sciences, Molinette Hospital, University of Studies of Turin Italy University of Palermo, Italy

*Corresponding author: Carlo Melloni, M.D, Department of Surgical, Oncological and Oral Sciences, Plastic and Reconstructive Surgery Unit, University of Palermo, Italy, Tel: +39 091 6554034; Fax: +39 091 6553720; E-mail: carlomelloni.unipa@gmail.com

Received date: April 25, 2015, Accepted date: September 1, 2015, Published date: September 5, 2015

Copyright: $\odot 2015$ Melloni C, et al. This is an open-access article distributed under the terms of the Creative Commons Attribution License, which permits unrestricted use, distribution, and reproduction in any medium, provided the original author and source are credited.

\begin{abstract}
Approximately $20-30 \%$ of patients affected by renal cell carcinoma (RCC) present with metastatic disease, and $20 \%$ to $40 \%$ undergoing nephrectomy for clinically localized disease will develop metastases. A 53 years old female patient developed a left submandibular swelling. Four years before she experienced a left radical nephrectomy for a clear cell tumor and two years later right kidney was removed for a cancer having the same histologic subtype. In that circumstance duodenal pancreasectomy was required for infiltration of pancreatic gland. A sialoadenectomy has been performed and pathology demonstrated an intraglandular neoplasm with characteristics of a clear renal cell carcinoma. Although it is extremely rare, submandibular salivary gland may be a site of RCC metastasis. Diagnosis of metastatic disease for patients affected by submandibular swelling with a previous history of RCC should be always considered.
\end{abstract}

Keywords: Clear cell renal carcinoma; Metastasis; Submandibular gland; Salivary gland metastasis

\section{Introduction}

RCC is an unpredictable tumor because of its clinical behavior and high metastatic potential. It accounts for $3 \%$ of all malignancies and is the most deadly urological malignancy with only $62 \%$ of the patients surviving 5 years in all stages. It can metastasize to any location in the body, and its propensity to metastasize to unusual sites has been well documented. Approximately $20-30 \%$ of patients present with metastatic disease and $20 \%$ to $40 \%$ undergoing nephrectomy, for clinically localized RCC, will develop metastases [1]. The proportion of occurrence with distant metastases increased with tumor size, $\mathrm{T}$ category and Fuhrman grade. According data of Swedish Kidney Cancer Registry [2] RCCs have an aggressive potential, resulting in distant metastases even in tumor of $1-2 \mathrm{~cm}$ in size. In other published series no patients with RCC developed metastases after surgery for a tumor $<2 \mathrm{~cm}$ during a median follow up of 7 years [3].

The most commonly involved organ is the lung, then lymph nodes, liver, bones, adrenal glands, opposite kidney, brain, heart, spleen, intestine, and skin follow with decreasing frequency in this order. It has long been known that RCC produces metastases of very unusual location and presentation.

Bennington and Beckwith gave an exhaustive and complete description of the differential diagnosis of metastases of RCC in 1975. In conclusion, secondary lesions arising from RCC may involve nearly every organ, including salivary glands [4]. Literature reports a predominance of parotid gland metastasis; submandibular salivary gland is a rare site of metastasis and descriptions are limited to few case reports.

\section{Case Report}

A 53 years old female patient developed a left submandibular swelling (Figure 1).

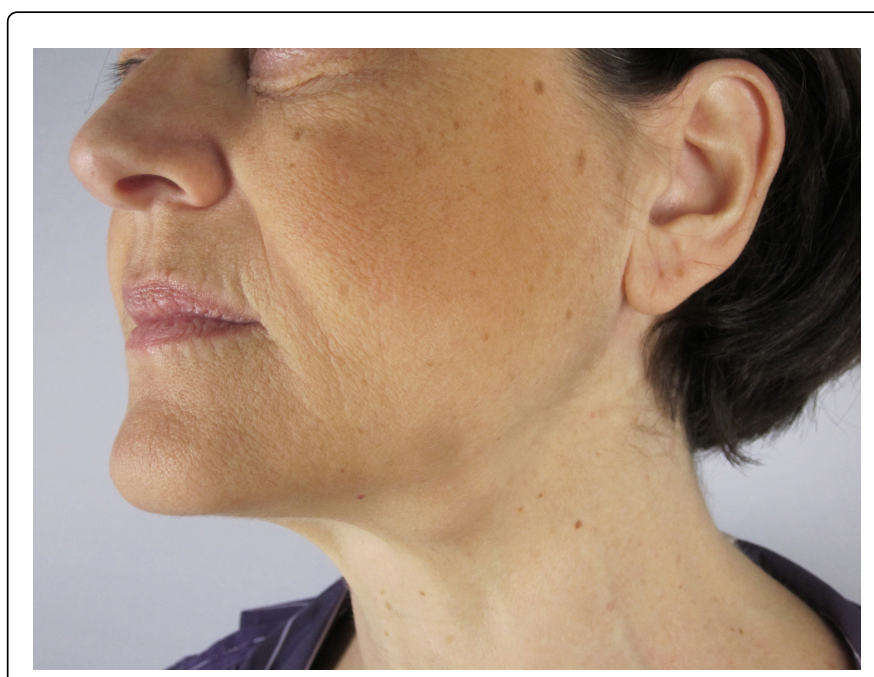

Figure 1: The left mandibular swelling appeared 4 years after a radical nephrectomy for a Clear Renal Cell Cancer.

The patient was initiated on hemodialysis as consequence of bilateral nephrectomy. In fact, 4 years before, she experienced a left radical nephrectomy for a clear cell tumor and 2 years later right kidney was also removed for a cancer having the same pathological figure. In that circumstance, duodenal pancreasectomy was required for infiltration of pancreatic gland. The submandibular lesion looked 
Page 2 of 3

rounded, measured about $4 \mathrm{~cm}$ in diameter; it had a hard consistency and was fixed and painful.

Preoperatively US of the swelling and head-neck CT scan with 3D rendering (Figure 2) Demonstrated a submandibular gland increased in size, hypoechoic, with regular edges and homogeneous density.

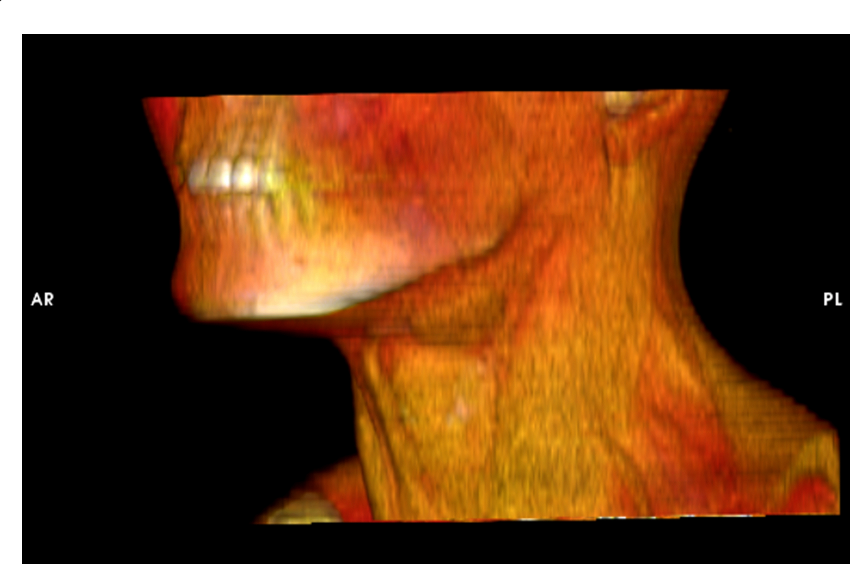

Figure 2: 3D rendering showing dimension and position of the submandibular swelling.

Fine needle aspiration and cytology showed us a "papillary cystadenoma lymphomatosum". This benign neoplasm with its intimidating histologic name, also called Warthin's tumor, is the second most common benign salivary gland neoplasm. Although it can occur elsewhere, it most commonly arises in the parotidgland (the only tumor virtually restricted to the parotid). Sialoadenectomy with marginal mandibular nerve sparing surgery were performed and histology demonstrated an intraglandular neoplasm referred to clear RCC metastasis.

\section{Discussion}

Metastatic renal cell carcinoma has a poor prognosis. Despite advances in biological and immune-based therapies, response rate for patients with metastatic RCC remain at about 15 to $25 \%$. About $75 \%$ of patients with metastatic renal carcinoma have metastases to the lung, $36 \%$ to the soft tissues, $20 \%$ to bone, $18 \%$ to liver, $8 \%$ to cutaneous sites and $8 \%$ to the central nervous system. Even if reported infrequently, head and neck region metastases may be linked to RCC in up to 8$15 \%$ of cases [1,5]. Complete removal of metastatic lesions, if technically feasible, can contribute to an improvement of clinical prognosis. In patients with synchronous metastatic spread, metastasectomy should be performed in case of resectable disease and good performance status, although the clinical prognosis is worse when compared with the occurrence of asynchronous metastases. Treatment of RCC metastasis in the head and neck is directed mainly towards palliation [6]. Excision is usually performed to control pain and to manage any potential complications from a space occupying mass in the head and neck region, including the brain. Reports of RCC in the head and neck region involve those in the nose, tongue, paranasal sinuses, larynx, mandible, temporal bone and thyroid gland $[7,8]$. The location of metastasis usually dictates the presenting symptoms [9]. In the oral cavity, the majority of metastases occur to the bones, especially involving the jaw. Only in 33\% of the cases are they seated in soft tissues, and this is usually associated with a bad prognosis. Submandibular salivary gland metastases are extremely rare and commonly referred to parotid gland. In our patient radiological and cytological findings have not been able to distinguish between benign or malignant disease and the presurgical diagnosis was Warthin's tumor. The mistake derived from oncocityc appearance of Warthin's tumor. Oncocytes are epithelial cells stuffed with mitochondria, which impart the granular appearance to the cytoplasm. Cytological sample showed neoplastic epithelial cells having an abundant, finely granular, eosinophilic cytoplasm. Nevertheless, lymphoid elements were absent while Warthin's tumor usually shows a dense lymphoid stroma or follicular germinal center beneath the epithelium. Immunohistochemical findings of the surgical specimen confirmed a clear RCC metastasis. In fact, cancer cells shoved CD10positivity, vimentin and cytocheratin $8 / 10$ coexpression, CEA and S100-negativity.

\section{Conclusion}

Although it is extremely rare, submandibular salivary gland may be a site of RCC metastasis. Accordingly, metastatic disease should be considered in the differential diagnosis for patients affected by submandibular swelling with a previous history of RCC. Radiological and cytological findings may not distinguish between primary and metastatic disease and the definitive diagnosis may derive only by pathological and immunohistochemical findings. Histologically differentiating among clear cell tumors with conventional light microscopy can be challenging. It can be especially difficult to distinguish between RCC metastasis and clear cell malignancies of the salivary glands, such as, acinic cell neoplasm, clear cell oncocytoma, mucoepidermoid carcinoma, primary clear-cell carcinoma and epithelial-myoepithelial carcinoma [9]. Immunohistochemical staining helps in this distinction, with RCC metastasis exhibiting focal cytokeratin positivity (versus minor salivary gland cancers showing diffuse positivity) and a strong reaction for vimentin [10].

\section{References}

1. Golimbu M, Joshi P, Sperber A, Tessler A, Al-Askari S, et al. (1986) Renal cell carcinoma: survival and prognostic factors. Urology 27: 291-301.

2. Guomundsson E, Hellborg H, Lundstam S, Erikson S, Ljungberg B; Swedish Kidney Cancer Quality Register Group (2011) Metastatic potential in renal cell carcinomas $7 \mathrm{~cm}$ : Swedish Kidney Cancer Quality Register data. Eur Urol 60: 975-982.

3. Kunkle DA, Crispen PL, Li T, Uzzo RG (2007) Tumor size predicts synchronous metastatic renal cell carcinoma: implications for surveillance of small renal masses. J Urol 177: 1692-1696.

4. Udager AM, Rungta SA (2014) Metastatic Renal Cell Carcinoma, Clear Cell Type, of the Parotid Gland: a case report, review of literature, and proposed algorithmic approach to salivary gland clear cell neoplasms in fine-needle aspiration biopsies. Diagn Cytopathol 42: 974-983.

5. Narea-Matamala G, Fernandez-Toro Mde L, Villalabeitía-Ugarte E, Landaeta-Mendoza M, Rojas-Alcayaga G (2008) Oral metastasis of renal cell carcinoma, presentation of a case. Med Oral Patol Oral Cir Bucal 13: E742-E744.

6. Fukuda M, Miyata M, Okabe K, Sakashita H (2002) A case series of 9 tumors metastatic to the oral and maxillofacial region. J Oral Maxillofac Surg 60: 942-944.

7. Som PM, Norton KI, Shugar JM, Reede DL, Norton L, et al. (1987) Metastatic hypernephroma to the head and neck. AJNR Am J Neuroradiol 8: 1103-1106.

8. Boles R, Cerny J (1971) Head and neck metastases from renal carcinomas. Mich Med 70: 616-618. 
Citation: Melloni C, Dispensa N, Tuttolomondo A, Melloni G, Cordova A (2015) Metastatic Renal Cell Carcinoma to Submandibular Gland: A Rare Occurrence. Anaplastology 4: 151. doi:10.4172/2161-1173.1000151

Page 3 of 3

9. Layfield LJ, Glasgow BJ (1993) Aspiration cytology of clear-cell lesions of the parotid gland: morphologic features and differential diagnosis. Diagn Cytopathol 9: 705-711.
10. Will TA, Agarwal N, Petruzzelli GJ (2008) Oral cavity metastasis of renal cell carcinoma: a case report. J Med Case Rep 2: 313. 